\title{
Understanding the relationship between subjective health complaints and satisfaction with life for people in prevocational training in Norway
}

\author{
Lina H. Ellingsen-Dalskau* \\ Department of Public Health Science \\ Norwegian University of Life Sciences \\ Email: lina.dalskau@nmbu.no
}

${ }^{*}$ corresponding author

\section{Bente Berget}

NORCE Norwegian Research Centre AS

Department of Sociology and Social Work

The University of Agder, Norway

Email: bebe@norceresearch.no

\section{Gunnar Tellnes}

Department of Community Medicine and Global Health

University of Oslo, Norway

School of Health Sciences

Kristiania University College, Norway

Email: gunnar.tellnes@medisin.uio.no

\section{Camilla Ihlebæk}

Department of Public Health Science

Norwegian University of Life Sciences

Faculty of Health and Welfare

Østfold University College

Email: camilla.ihlebak@nmbu.no 


\begin{abstract}
Background and aim: In Norway, a large part of the population is dependent on disability benefits. The main reasons for this are related to long-term musculoskeletal pain and psychological complaints. Prevocational rehabilitation, aimed at increasing participation in working life, targets people in need of a sheltered vocational environment. This group has been found to report a very high level of health complaints. Therefore, a better understanding of the psychological mechanisms affecting satisfaction with life for people who experience subjective health complaints could be important for tailoring more optimal vocational rehabilitation initiatives for these individuals. This study aimed to investigate the possible mediator role of basic psychological need satisfaction, described in self-determination theory, in the relationship between subjective health complaints and satisfaction with life.
\end{abstract}

Methods: A total of 201 adult participants attending prevocational training on care farms in Norway answered a questionnaire, including demographic questions and standardised instruments on subjective health complaints, basic psychological need satisfaction and satisfaction with life. Analyses were conducted using a structural equation model.

Results: Most of the participants had been out of work for more than one year, had a high prevalence of subjective health complaints and a low level of satisfaction with life. The structural equation model showed that basic psychological need satisfaction mediated the negative association between psychological health complaints and satisfaction with life.

Conclusion: The results indicate that even though health complaints remain, prevocational programs can counteract some of the negative associations between subjective health complaints and satisfaction with life by creating contexts that support basic psychological needs that are important for well-being and functioning. Providing clients with understanding, guidance, positive feedback, meaningful tasks and a close, supportive social community, has been found to facilitate satisfaction of basic psychological needs in prevocational training on care farms. 
Keywords: Self-determination theory, basic psychological needs, vocational rehabilitation, return to work, care farms, psychological complaints, musculoskeletal pain

\section{Introduction}

In Norway, more than one out of 10 people (10.4\%) between the ages of 18 and 67 are recipients of disability benefits from the Norwegian Labour and Welfare Administration (NAV). This is similar to the numbers reported in 2010 by OECD (2010) where it was found that Norway had a higher level of disability benefit recipients compared to most of the Nordic countries and almost twice the average level reported in the other OECD countries $(5.7 \%)$ (OECD, 2010). This is a concern, because employment has been associated with obtaining economic resources as well as being central to an individual's level of satisfaction with psychosocial needs, identity, social roles and status (Blustein, 2008; Waddell \& Burton, 2006). Additionally, not working may have severe negative consequences for an individual's psychological and physical health, such as experiencing more psychological distress and long-term illness (Blustein, 2008; Waddell \& Burton, 2006). Therefore, several initiatives have been taken in Norway, as well as other Nordic countries, to develop vocational rehabilitation services to increase participation in working life (Thorsen et al., 2015).

\section{Prevocational training on care farms}

Prevocational training is one such initiative. Prevocational training, also known as transitional employment, offers a temporary adapted and sheltered work environment for individuals with reduced capabilities to find work (NAV, 2020b). The aim is to convey the basic expectations of ordinary employment and improve vocational and social skills, enabling individuals to eventually move on to vocational rehabilitation and competitive employment at a later stage (Liberman, 2008; NAV, 2020b; Rossler, 2006). In Norway, a number of care farms offer prevocational training. Care farms are commercial farms providing practical and varied farming activities adjusted to the clients' interests and capacities to promote health to a variety of different client groups (Hassink \& van Dijk, 2006; Hine et al., 2008; Ihlebæk et al., 2016; Pedersen et al., 2016). On these farms, health promotion helps ensure that the clients become active in maintaining and developing their own health $(\mathrm{WHO}, 2016)$ by experiencing support 
from others, improving their coping ability, developing skills and gaining capabilities within the context of a green environment (Sempik et al., 2010). This is also in line with the prevocational training aim of providing individuals with basic vocational and social skills to eventually make the transfer to competitive employment.

Thus, prevocational training on care farms is an innovative and diverse rehabilitation initiative, contributing to the variety of services offered within the Norwegian welfare system. The clients are referred from different health and social care agencies, comprising health care institutions at the municipal level and NAV. Clients visit the farms one to five days a week. The service is typically run by the farmer or the farmer's spouse (Ellingsen-Dalskau et al., 2016); it entails a variety of practical work tasks, including livestock farming, forest management, the cultivation of grains, fruits or vegetables or helping to run other businesses on the farm, such as working in a farm shop or café (Pedersen et al., 2016).

\section{Subjective health complaints}

As with prevocational programs in general, prevocational training on care farms supports people in need of a sheltered work environment that are often dependent on social security benefits. Being out of work and receiving social security benefits may be related to some of the highest self-reported number of symptoms in the Norwegian population, including musculoskeletal pain and psychological and gastrointestinal complaints (Kjeldsberg et al., 2013). These symptoms are known as subjective health complaints, and they constitute subjective complaints with few or no objective findings (Eriksen \& Ihlebæk, 2002). Most people experience subjective health complaints as normal everyday complaints. However, for some, these complaints become severe and long-lasting (Ihlebæk et al., 2002). The negative consequences associated with high numbers of health complaints include an increase in functional problems and a reduction in general health, sleep quality, psychological health, health-related quality of life and self-rated health (Bruusgaard et al., 2012; Kamaleri, Natvig, Ihlebaek, Benth, \& Bruusgaard, 2008; Kamaleri, Natvig, Ihlebaek, \& Bruusgaard, 2008; Kjeldsberg et al., 2013; Ree et al., 2014; Tveito et al., 2004). Studies have also found a higher number of subjective health complaints to be related to unemployment, longer periods of sickness 
absence, and being a recipient of social security benefits (Kjeldsberg et al., 2013;

Poulsen et al., 2013; Roelen et al., 2010; Tveito et al., 2002). The two main reasons for long-term sick-leave and disability in Norway are related to musculoskeletal pain and psychological complaints (Brage et al., 2010; Ihlebæk et al., 2007; Waddell, 2006). Furthermore, a longitudinal study by Kamaleri et al. (2009) showed that an increased number of pain sites predicted future disability 14 years after the complaints were reported. Thus, for people in prevocational training, subjective health complaints may complicate their ability to return to work, which has been found to be a complex and long-lasting process (Øyeflaten et al., 2012).

However, very few research studies have attempted to identify the psychological mechanisms that can clarify and explain how subjective health complaints may influence the lives of people in prevocational training. As the common goal of vocational training is not necessarily to cure participants' symptoms, but rather to facilitate mastery of their working life, a better understanding of these mechanisms could be useful for tailoring prevocational training on care farms. This insight could also prove valuable for optimisation of work rehabilitation services in general.

\section{Self-determination theory}

The three basic psychological needs described by the self-determination theorycompetence, relatedness and autonomy—may be useful for gaining a better understanding of how living with a high level of subjective health complaints influences one's well-being (Deci \& Ryan, 2000, 2008a). Competence is the need to be effective in dealing with the environment; relatedness reflects the need to be connected to and to care for others; and autonomy is the universal desire to experience volition and be causal agents in one's life (Deci \& Ryan, 2000). According to self-determination theory, humans' natural tendency for growth, optimal motivation and function is promoted through contexts that support the satisfaction of these basic psychological needs (Deci \& Ryan, 2000, 2008a; Ryan \& Deci, 2000). A vast and growing body of empirical literature has shown the benefits of basic psychological need satisfaction, both in general and in specific life domains (Deci \& Ryan, 2008b). Researchers have found that this satisfaction facilitates autonomous and internal motivation, which have been 
persistently related to psychological health, self-esteem, well-being, the experience of meaningfulness, flow and daily well-being (Deci \& Ryan, 2008b; Gagné \& Deci, 2005; Kowal \& Fortier, 1999; Sheldon et al., 1996). Farholm et al. (2016) also noted the importance of experiencing need satisfaction in vocational rehabilitation to improve well-being and return to work. However, contexts that do not support satisfaction of basic psychological needs undermine self-motivation, performance and wellness (Reis et al., 2000; Turner et al., 2009).

The importance of basic psychological need satisfaction for function and well-being underlie the current aim to investigate basic psychological need satisfaction as a possible mediator in the relationship between musculoskeletal pain and psychological complaints, and satisfaction with life for clients in prevocational training on care farms in Norway. We hypothesise that musculoskeletal pain and psychological complaints have a negative association with satisfaction with life, in line with research showing the negative consequences of subjective health complaints on function and well-being. Furthermore, we hypothesise that basic psychological need satisfaction mediates the relationship between subjective health complaints and satisfaction with life, where more complaints are expected in association with lower satisfaction of basic psychological needs and satisfaction with life.

\section{Methods}

\section{Recruitment and participants}

The participants in this study were clients in prevocational training on Norwegian care farms. In 2011, questionnaires were mailed to all care farms in Norway, and the farmers were asked to distribute these questionnaires to clients ranging in age from 18 to 66 (working age population) who received welfare benefits from NAV and who had participated in prevocational training for at least one month. This resulted in a sample of 201 adult participants attending prevocational training from 65 different care farms. The sample consisted of $86(43 \%)$ men and $115(57 \%)$ women, with a mean age of 35.7 years (standard deviation [SD] 11.9, range: 19-65 years). The lack of a register of care farm clients made it difficult to calculate an exact response rate. However, based on information obtained from the care farmers, a conservative estimate indicated that 
approximately $45 \%$ of the clients who received the questionnaires from the farmers responded to the survey.

\section{Measurements}

Descriptive questions

The questionnaire contained questions about the participants' demographic characteristics and background information, including sex, age, marital status, level of education and time out of work.

\section{Subjective health complaints}

The participants answered the questions in the subjective health complaints inventory, shown to be a reliable and valid instrument (Ihlebæk et al., 2004). Using a 4-point scale $(0=$ not at all, $1=$ a little, $2=$ some and $3=$ severe $)$, the participants indicated how they had experienced 29 common health complaints during the last 30 days (Eriksen et al., 1999). The complaints can be divided into five subscales: musculoskeletal pain, psychological complaints, gastrointestinal problems, allergies and flu (Eriksen et al., 1999). In this study, we only used the musculoskeletal pain subscale (headache, neck pain, upper back pain, lower back pain, arm pain, shoulder pain, migraine and leg pain during physical activity) and psychological complaints subscale (extra heartbeats, heat flashes, sleep problems, tiredness, dizziness, anxiety and sadness/depression) in the main analysis. We then summarised individual item answers on the musculoskeletal pain subscale $(\alpha=.83)$ and the psychological complaints subscale $(\alpha=.82)$ to create two variables reflecting the level of severity of these complaints (Eriksen et al., 1999).

\section{Basic psychological needs}

The participants answered the questions in the general need satisfaction scale (Deci \& Ryan, 2000; Gagné, 2003), which research studies have defended as valid and reliable for measuring need satisfaction in several domains in life (Johnston \& Finney, 2010; La Guardia et al., 2000; Van den Broeck et al., 2010; Vlachopoulos \& Michailidou, 2006). The participants evaluated 21 items indicating the extent of how their basic psychological need for competence ( 6 items), relatedness ( 8 items) and autonomy (7 items) were generally satisfied in their lives, rated on a Likert scale ranging from 1 (not at all true) to 7 (completely true). The subscales consisted of items, such as "I often do not feel very 
capable" (competence), "People in my life care about me" (relatedness) and "I feel pressured in my life" (autonomy). Afterwards, we calculated the mean scores of the subscales of autonomy $(\alpha=.64)$, competence $(\alpha=.64)$ and relatedness $(\alpha=.81)$. The Cronbach's alpha scores (Cronbach, 1951) of autonomy and competence were somewhat lower than the recommended values, indicating overall acceptable/good internal consistency (suggested range from .70 to .95) (Tavakol \& Dennick, 2011). These low values could indicate a poor interrelatedness between the items or, alternatively, that competence and autonomy are heterogeneous constructs (Tavakol \& Dennick, 2011). However, because these are standardised scales, and because the Cronbach's alpha values were just below .70, all the items were included in the analysis.

\section{Satisfaction with life}

Lastly, the participants answered the questions of the satisfaction with life scale (Diener et al., 1985), which is a valid and reliable measure of the global cognitive judgement of satisfaction with life (Pavot et al., 1991). The participants indicated on a 7-point Likert scale ranging from 1 (strongly disagree) to 7 (strongly agree) their agreement with five items, such as "In most ways my life is close to my ideal" and "The conditions of my life are excellent". The total score ranges from 5 to 35 , and it can be divided into six categories reflecting one's satisfaction with life (Diener, 2006). Three categories are below the neutral mid-point of 20: Extremely dissatisfied (5-9), Dissatisfied (10-14) and Slightly dissatisfied (15-19). Three categories are above the neutral mid-point: Slightly satisfied (21-25), Satisfied (26-30) and Extremely satisfied (31-35). We also summarised the items to create a score reflecting the participants' overall satisfaction with life $(\alpha=.90)$.

\section{Statistical analysis}

We performed statistical tests using SPSS version 23.0, with the level of statistical significance set to 0.05 . A structural equation model, where numerous linear models can be fit simultaneously (Byrne, 2010), was used to examine the mediator function of basic psychological need satisfaction in the relationship between subjective health complaints and satisfaction with life (Figure 1 and Figure 2). Structural equation modelling was preferred because it provides a graphic statistical model that describes the underlying structure of the variables in a transparent way. Structural equation models take a 
confirmatory approach (Byrne, 2010), which means that models should be constructed based on relevant theoretical and empirical information (Hox \& Bechger, 1998). In relation to the sample size, although somewhat debated, it has been suggested that an overall sample size of around 200 is considered sufficiently large (Kline, 2011). Therefore, our sample size of 201 participants and the application of the selfdetermination theory indicated that structural equation modelling could be a useful way to investigate the relationships between the variables. We created the models using Analysis of Moments Structure (AMOS) version 23.0.

\section{Structural equation modelling}

The structural equation model had three levels, which were created to investigate the possible mediator role of basic psychological need satisfaction in the relationship between subjective health complaints and satisfaction with life (Baron \& Kenny, 1986) (Figure 1 and Figure 2). The first level in the model consisted of the exogenous variables, musculoskeletal pain and psychological complaints. The second level in the model consisted of the latent mediating variable: need satisfaction. This was a composite score created from the mean scores on the subscales measuring satisfaction of the three basic psychological needs of competence, relatedness and autonomy. The last level in the model consisted of the endogenous variable: satisfaction with life. To avoid excluding cases with missing values $(16.3 \%)$ from the analysis, the missing values $(1.4 \%$ in total) were imputed using expectation maximisation (EM) (Peters \& Enders, 2002; Sterne et al., 2009). We then ran the full model including the pathways between all the exogenous and endogenous variables, calculating and reducing until only significant regressions remained. Next, we calculated a multigroup invariance test exploring the differences between men and women. This showed significant gender differences; therefore, we separately analysed men and women, resulting in two parsimonious models, one for men (Figure 1) and one for women (Figure 2). Finally, we reran the parsimonious models using the original data, resulting in virtually similar models.

\section{Ethics}

This study was approved by the Norwegian Regional Ethics Committee for Southeast Norway (2010/2042) and the Norwegian Social Science Data Services. Informed written consent was obtained from all the participants included in the study. Furthermore, all the 
procedures performed in this study involving human participants were in accordance with the 1964 Declaration of Helsinki and its later amendments or comparable ethical standards.

\section{Results}

\section{Descriptive statistics}

A large proportion of participants had low levels of education, with $86.1 \%$ reporting having completed only lower or upper secondary school; moreover, the majority of the participants lived alone (Table 1). More than $62 \%$ reported having been out of work for more than one year and more than $16 \%$ had never been employed (Table 1).

Table 1. Proportion (\%) of women and men in categories related to marital status, level of education and time out of work

\begin{tabular}{lccc}
\hline Variables & $\begin{array}{c}\text { Total }(\mathrm{n}= \\
201)\end{array}$ & $\begin{array}{c}\text { Women }(\mathrm{n} \\
=115) \\
\mathrm{N}(\%)\end{array}$ & $\begin{array}{c}\text { Men }(\mathrm{n}= \\
86) \\
\mathrm{N}(\%)\end{array}$ \\
\hline Marital status* & $\mathrm{N}(\%)$ \\
$\quad$ Unmarried & $128(63.3)$ & $60(53.1)$ & $68(79.1)$ \\
$\quad$ Divorced/separated & $27(13.6)$ & $15(13.3)$ & $12(14)$ \\
Spouse/partner/cohabitant & $44(22.1)$ & $38(33.6)$ & $6(7)$ \\
Education* & & \\
Lower secondary school (up to 9 years) & $81(40.9)$ & $47(42)$ & $34(39.5)$ \\
Upper secondary school (10-12 years) & $92(46.5)$ & $48(42.9)$ & $44(51.2)$ \\
University/college (more than 12 years) & $17(8.6)$ & $11(9.8)$ & $6(7)$ \\
Other & $8(4)$ & $6(5.4)$ & $2(2.3)$ \\
Time out of work* & & & \\
0-6 months & $19(9.7)$ & $11(9.9)$ & $8(9.6)$ \\
6-12 months & $22(11.2)$ & $14(12.5)$ & $8(9.5)$ \\
1-2 years & $33(16.9)$ & $18(16)$ & $15(17.8)$ \\
2-5 years & $40(20.4)$ & $23(20.5)$ & $17(20.2)$ \\
More than 5 years & $49(25)$ & $27(24.1)$ & $22(26.2)$ \\
No work experience & $33(16.8)$ & $19(17)$ & $14(16.7)$ \\
\hline
\end{tabular}

*Indicates missing values in category (range of missing from 1-2.6\%)

\section{Subjective health complaints}

A total of $99.5 \%$ of the participants reported having experienced at least one health complaint during the last 30 days. Both women and men reported a high number of health complaints $(\mathrm{M}=11.7, \mathrm{SD}=6.2)(\mathrm{t}(198)=-2.81$, non-significant [n.s.] $)$, and more than $63 \%$ had experienced 10 or more complaints in the last 30 days. The most commonly reported single complaints for both men and women were headache, tiredness, anxiety, 
sadness/depression and sleep problems. However, women had a significantly higher prevalence of headache $(80.0 \%$ women and $52.3 \%$ men) and tiredness $(79.1 \%$ for women and $61.6 \%$ for men) in comparison to men. The overall prevalence of psychological complaints was $90.0 \%$ (94.8\% for women and $83.7 \%$ for men); it was $86.0 \%$ for musculoskeletal pain $(92.2 \%$ women and $77.9 \%$ men). Moreover, $81.0 \%$ ( $88.7 \%$ women and $72.1 \%$ men) of the participants reported having both musculoskeletal pain and psychological complaints. The mean severity scores for psychological complaints $(M=7.7, S D=4.89)$ and musculoskeletal pain $(M=6.6, S D=5.45)$ were included in the structural equation model (Table 2). Women had significantly higher mean severity scores than men on both psychological complaints $(t(198)=-2.82, p<.005)$ and musculoskeletal pain $(\mathrm{t}(197)=-3.29, \mathrm{p}<.001)$.

\section{Structural equation models}

Table 2 presents the mean, SD, range and Pearson's correlation coefficients for the variables included in the models. Except for the non-significant correlation between musculoskeletal pain and relatedness, the correlation coefficients indicate that the variables are significantly related in the hypothesised direction. This supports our hypothesis that musculoskeletal pain and psychological complaints are negatively associated with satisfaction with life, and that basic psychological need satisfaction is related to subjective health complaints and satisfaction with life.

\section{Table 2}

\begin{tabular}{lcccccc} 
Mean, standard deviation (SD), range and Pearson's correlation coefficients for the variables in the structural equation model \\
\hline Variables & $\begin{array}{c}\text { Musculoskeletal } \\
\text { pain }\end{array}$ & $\begin{array}{c}\text { Psychological } \\
\text { complaints }\end{array}$ & $\begin{array}{c}\text { Competence } \\
\text { Relatedness }\end{array}$ & $\begin{array}{c}\text { Autonomy } \\
\text { Satisfaction } \\
\text { with life }\end{array}$ \\
\hline $\begin{array}{l}\text { Musculoskeletal pain } \\
\text { Psychological complaints }\end{array}$ & - & $.536^{* *}$ & $-.159^{*}$ & -.026 & $-.216^{* *}$ & $-.186^{* *}$ \\
Competence & & - & $-.437^{* *}$ & $-.391^{* *}$ & $-.460^{* *}$ & $-.461^{* *}$ \\
Relatedness & & & - & $.617^{* *}$ & $.632^{* *}$ & $.496^{* *}$ \\
Autonomy & & & & - & $.628^{* *}$ & $.455^{* *}$ \\
Satisfaction with life & & & & $-572^{* *}$ & - \\
\hline Mean & 6.60 & 7.70 & 4.44 & 5.15 & 4.70 & 16.21 \\
SD & 5.45 & 4.89 & 1.07 & 1.06 & 1.00 & 7.80 \\
Range & $0-23$ & $0-21$ & $1.3-7$ & $1.6-7$ & $1.9-7$ & $5-35$ \\
\hline
\end{tabular}

*Significant at the .005 level (2-tailed)

**Significant at the .001 level (2-tailed) 
Figure 1

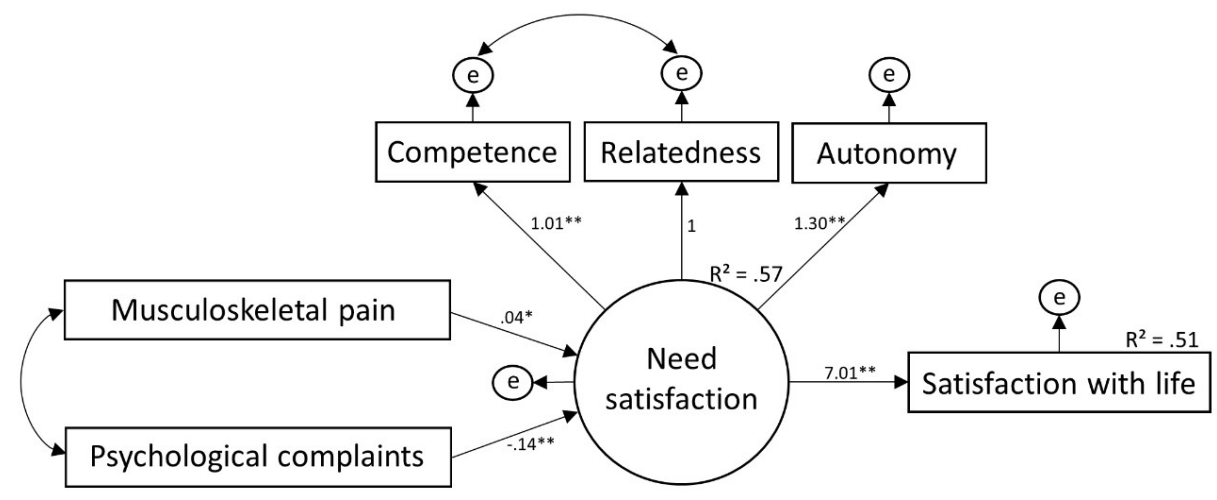

Structural equation model for men with standardised regression weights $(\beta)$ showing the pathways between the variables, musculoskeletal pain and psychological complaints, need satisfaction and satisfaction with life. $R^{2}$ values are given for each of the two dependent variables. e represents the measurement error associated with the latent and observed variables. Regression weights followed by * are significant at a .05 level, and those followed by ** are significant at a .01 level.

All the pathways displayed in the structural equation model for men were significant at the .05 or .01 level (Figure 1). The first exogenous variable, musculoskeletal pain, was positively associated with the mediator variable, need satisfaction $(\beta=.04)$. The second exogenous variable, psychological complaints, was negatively associated with need satisfaction $(\beta=-.14)$. Furthermore, need satisfaction was positively associated with satisfaction with life $(\beta=7.01)$. A total of $57 \%$ of the variance in need satisfaction was explained by musculoskeletal pain and psychological complaints, and $51 \%$ of the variance in satisfaction with life was explained by need satisfaction. 


\section{Figure 2}

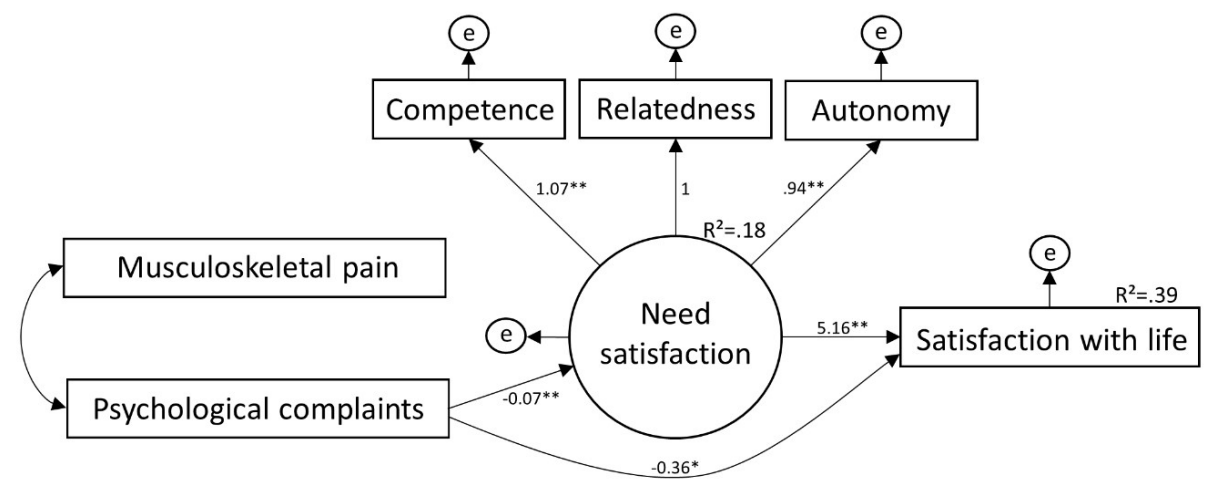

Structural equation model for women with standardised regression weights $(\beta)$ showing the pathways between the variables, musculoskeletal pain and psychological complaints, need satisfaction and satisfaction with life. $R^{2}$ values are given for each of the two dependent variables. e represents the measurement error associated with the latent and observed variables. Regression weights followed by * are significant at a .05 level, and those followed by ${ }^{* *}$ are significant at a .01 level.

All the pathways displayed in the model for women were significant at the .05 or .01 level (Figure 2). The first exogenous variable, musculoskeletal pain, was unrelated to any of the outcome variables in the model. The second exogenous variable, psychological complaints, was negatively associated with the mediator variables, need satisfaction ( $\beta$ $=-.07)$ and satisfaction with life $(\beta=-.36)$. Furthermore, need satisfaction was positively associated with satisfaction with life $(\beta=5.16)$. A total of $18 \%$ of the variance in need satisfaction was explained by psychological complaints, and $39 \%$ of the variance in satisfaction with life was explained by the combination of psychological complaints and need satisfaction.

The statistical tests chi-square (X2), relative/normed chi-square (X2/df), Tucker-Lewis index (TLI), comparative fit index (CFI) and root mean square error of approximation (RMSEA) were used to evaluate the model fit for the structural equation models. The fit statistics indicated an overall acceptable to good fit of the models to the data for both men, as seen in Figure $1(\mathrm{X} 2(7)=9.34, \mathrm{p}>.05 ; \mathrm{X} 2 / \mathrm{df}=1.33, \mathrm{TLI}=.981, \mathrm{CFI}=.991$, RMSEA = .063) and women, as seen in Figure $2(X 2(8)=12.56, p>.05 ; X 2 / d f=1.57$, $\mathrm{TLI}=.959, \mathrm{CFI}=.978, \mathrm{RMSEA}=.071)$. 


\section{Discussion}

As expected, the results showed that people in prevocational training on care farms in Norway had a high level of subjective health complaints and a low level of satisfaction with life. Furthermore, the structural equation models showed that a high level of psychological complaints had a negative association with satisfaction with life, and that this relationship was mediated by satisfaction with basic psychological needs, competence, relatedness and autonomy for both men and women. Contrary to what we hypothesised, we did not find the same relationship for musculoskeletal pain and satisfaction with life.

\section{Level of subjective health complaints, satisfaction with life and time out of work}

First, the high level of subjective health complaints is in accordance with Kjeldsberg et al. (2013), who found that unemployed individuals and recipients of social security benefits represent segments of the population with a high number of symptoms. Psychological complaints were most commonly reported in our study, with a prevalence of $90 \%$, which is high compared to the $65 \%$ prevalence in the normal population (Ihlebæk et al., 2002). This is in accordance with Steigen et al. (2018) who, in their sample of young adults attending nature-based services in Norway, found that more than $50 \%$ reported mental health problems. In the current study participants also commonly reported musculoskeletal pain, and the degree of comorbidity between musculoskeletal pain and psychological complaints was high, as more than $80 \%$ of the participants had both types of health complaints.

The scores on satisfaction with life were accordingly low. More than two-thirds of the sample fell beneath the neutral mid-point of the scale, which is lower than what is usually found in Western countries (Pavot \& Diener, 1993). Almost one-third of participants were classified as dissatisfied with their life, and one in five were extremely dissatisfied. These findings indicate that most clients in prevocational training on care farms struggle in multiple areas of life (Diener, 2006).

As expected for clients in prevocational programs, most of the participants in the current study had been out of work for more than one year. One in five had been out of work for 
two to five years and one in four for more than five years. This is considerably longer than clients in other vocational rehabilitation clinics in Norway (Øyeflaten et al., 2016). In addition, $16 \%$ of the participants had no work experience at all. Therefore, the high level of subjective health complaints, the low level of satisfaction with life, the weak connection to the ordinary work force, as well as a generally low education level indicate that these individuals experience several health and functional problems connected to a more challenging return to work process (Bruusgaard et al., 2012; Gjesdal \& Bratberg, 2003; Kamaleri, Natvig, Ihlebaek, Benth, \& Bruusgaard, 2008; Kamaleri, Natvig, Ihlebaek, \& Bruusgaard, 2008; Kamaleri et al., 2009; Piha et al., 2010; Poulsen et al., 2013; Ree et al., 2014; Tveito et al., 2002; Tveito et al., 2004).

\section{The mediator role of basic psychological needs}

Furthermore, results from the structural equation models corroborate earlier findings that a high level of subjective health complaints may have negative consequences, as a high degree of psychological complaints was negatively associated with satisfaction with life. We identified satisfaction of the three basic psychological needs, competence, relatedness and autonomy, as a mediator in this relationship. Individuals with a higher severity of psychological complaints reported less satisfaction of basic psychological needs and lower satisfaction with life. This fits well with the self-determination theory framework, which views positive human growth and function as a result of contexts that support the satisfaction of basic psychological needs (Deci \& Ryan, 2000; Ryan \& Deci 2000). In line with this theory, the associations indicate that a high degree of psychological health complaints may create a context that makes it difficult for individuals to satisfy their basic psychological needs for competence, relatedness and autonomy, which is associated with a lower satisfaction with life.

The mediator function of basic psychological need satisfaction was similar for men and women. The only significant difference was that the negative association between psychological complaints and basic psychological need satisfaction was stronger for men than women. This could also explain why the relationship between psychological complaints and satisfaction with life was fully mediated for men, while the same relationship was only partially mediated for women. Therefore, it seems that men with a high degree of psychological complaints find it more difficult to satisfy their basic 
psychological needs than women, making them more vulnerable when experiencing those psychological complaints. This is in line with the findings of Gjesdal et al. (2008), who found that, of people on certified sick leave with a psychiatric diagnosis, men had a higher risk of transitioning to a disability pension than women. This gender difference could be explained by the differences in vulnerability, risk factors and coping mechanisms that exist between men and women in relation to experiencing and developing mental health problems (Rosenfield \& Mouzon, 2013). For example, women usually have larger primary social networks and they engage in close social ties more often than men (Rosenfield \& Mouzon, 2013), which could provide women with an alternative way of satisfying their basic psychological needs.

Somewhat surprisingly, musculoskeletal pain did not influence basic psychological need satisfaction and satisfaction with life in the same way as psychological complaints did. However, the strong relationship between psychological complaints and basic psychological needs may reflect the similarity of these concepts, as they both represent mental processes. Other factors or mechanisms related to physical functioning could be more relevant to understanding how musculoskeletal pain influences satisfaction with life. This is supported by Øyeflaten et al. (2016), who identified poor physical function as a mediator in the relationship between musculoskeletal pain and fear avoidance beliefs for patients in vocational rehabilitation.

\section{The psychosocial dimension of subjective health complaints}

The findings from the current study indicate that a lack of basic psychological need satisfaction represents one important psychological mechanism that influences satisfaction with life when people have a high level of psychological health complaints. This provides a better understanding of why subjective health complaints may lead to poor function, reduced quality of life and problems related to work participation as reported in earlier research. It also underlines an important psychosocial component of having a high degree of subjective health complaints. From the self-determination theory perspective, the results indicate that a focus on basic psychological need satisfaction in the context of prevocational programs could help reduce some of the negative influences that psychological complaints may have on satisfaction with life by facilitating autonomous motivation, function and well-being, even though the complaints remain 
(Deci \& Ryan, 2000, 2008a; Ryan \& Deci, 2000). This is in line with Farholm et al. (2016), who found that providing support for autonomy, competence and relatedness improved well-being, physical activity and return to work for patients in vocational rehabilitation Two studies have investigated basic psychological needs for clients in prevocational training on care farms. These studies found that doing something useful and meaningful in a flexible, but structured work environment, as well as being part of a supportive social community providing understanding, acknowledgement, positive feedback and guidance, was important for creating a need supportive context (Ellingsen-Dalskau, Berget et al., 2016; Ellingsen-Dalskau, Morken et al., 2016)

\section{Methodological considerations}

Some limitations should be considered when interpreting the results of this study. First, the study's cross-sectional design means that causality cannot be inferred (Sedgwick, 2014). Therefore, the direction of the pathways between the variables in the structural equation models could also go in the opposite direction. However, the application of the self-determination theory framework is a strength of the study, ensuring a sound rationale for the postulated direction of the relationships in the models (Hox \& Bechger, 1998). Another limitation was the lack of an official register of care farm clients at the time of this study was conducted. Thus, we had to rely on the farmers to distribute both the invitations to participate and the questionnaires to the clients. Consequently, we do not have exact information about the response rate or the clients who refused to participate in the study. A few farmers communicated that they did not ask attendees with a very low functional level to participate, as they considered it to be too much of a burden for those individuals. This means that we cannot know if the participants are representative of farm-based prevocational training clients in Norway. Still, the extensive national mapping of prevocational programs, the close follow-up of the farmers during the recruitment process, together with clear written inclusion criteria, may have ensured a higher degree of sample representativeness. Therefore, the results could be applicable for clients in prevocational training on care farms, and they could also have relevance for individuals in other types of prevocational programs or for people who have been out of work for a long time and struggle with a high level of subjective health complaints. However, the prevalence of subjective health complaints and satisfaction with life may not be as transferable, whilst the associations between the variables found in the 
structural equation models may be more transferable, as these results are less likely to be influenced by a possible selection bias (Rothman, 2012).

Finally, it should be noted that these data were collected in 2011; thus, the relevance of the findings could be impacted. However, these prevocational programs are still provided at care farms in Norway, where the same training is offered to the same group of clients. Therefore, a better understanding of the relationship between subjective health complaints, basic psychological need satisfaction and satisfaction with life for this group of people is still relevant and important.

\section{Conclusion}

The clients in prevocational training on care farms in this study had a high level of psychological health complaints, which was negatively associated with satisfaction with life. Satisfaction of basic psychological needs was found to be an important mediator of this association. Based on the self-determination theory, the study's findings indicate that psychological health complaints may lead to reduced function, well-being and problems related to work participation for these individuals by creating a context where basic psychological needs are difficult to satisfy. This seems to be especially true for men, where the association between psychological complaints and psychological need satisfaction was particularly strong. Therefore, prevocational programs should focus on offering basic psychological need supportive environments to counteract some of the negative consequences related to having a high degree of psychological health complaints and to facilitate well-being and functioning. Providing clients with understanding, guidance, positive feedback, meaningful tasks and a close supportive social community has been found to be important for the satisfaction of basic psychological needs in the prevocational training context on care farms. This could potentially aid the process of returning to ordinary work for individuals who have been out of work for a long time and struggle with a high level of psychological complaints. More effective and diverse work rehabilitation services will contribute to a viable welfare system and facilitate social integration and security by enhancing return to work. 


\section{References}

Baron, R. M., \& Kenny, D. A. (1986). The moderator mediator variable distinction in social psychological-research: Conceptual, strategic, and statistical considerations. Journal of Personality and Social Psychology, 51(6), 11731182. https://doi.org/10.1037/0022-3514.51.6.1173

Blustein, D. L. (2008). The role of work in psychological health and well-being: A conceptual, historical, and public policy perspective. American Psychologist, 63(4), 228-240. https://doi.org/10.1037/0003-066X.63.4.228

Brage, S., Ihlebæk, C., Natvig, B., \& Bruusgaard, D. (2010). Musculoskeletal disorders as causes of sick leave and disability benefits. Tidsskrift for Den Norske Legeforening, 130, 2369-2370. https://doi.org/10.4045/tidsskr.10.0236

Bruusgaard, D., Tschudi-Madsen, H., Ihlebaek, C., Kamaleri, Y., \& Natvig, B. (2012). Symptom load and functional status: Results from the Ullensaker population study. BMC Public Health, 12, 1085. https://doi.org/10.1186/1471-2458-121085

Byrne, B. M. (2010). Structural equation modeling with AMOS: Basic concepts, applications, and programming (2nd ed.). New York Routledge, Taylor \& Francis Group.

Cronbach, L. J. (1951). Coefficient alpha and the internal structure of tests. Psychometrika, 16(3), 297-334. https://doi.org/10.1007/BF02310555

Deci, E. L., \& Ryan, R. M. (2000). The "What" and "Why" of goal pursuits: Human needs and the self-determination of behavior. Psychological Inquiry, 11(4), 227-268. https://doi.org/10.1207/S15327965PLI1104 01

Deci, E. L., \& Ryan, R. M. (2008a). Self-determination theory: A macrotheory of human motivation, development, and health. Canadian Psychology/Psychologie Canadienne, 49(3), 182-185. https://doi.org/10.1037/a0012801

Deci, E. L., \& Ryan, R. M. (2008b). Facilitating optimal motivation and psychological well-being across life's domains. Canadian Psychology/Psychologie Canadienne, 49(1), 14-23. https://doi.org/10.1037/0708-5591.49.1.14

Diener, E. (2006). Understanding scores on the Satisfaction with Life Scale. https://internal.psychology.illinois.edu/ ediener/Documents/Understanding\%2 0SWLS\%20Scores.pdf

Diener, E., Emmon, R. A., Larsen, R. J., \& Griffin, S. (1985). The Satisfaction with Life Scale. Journal of Personality Assessment, 49(1), 71-75. https://doi.org/10.1207/s15327752.jpa4901 13

Ellingsen-Dalskau, L. H., Berget, B., Pedersen, I., Tellnes, G., \& Ihlebæk, C. (2016). Understanding how prevocational training on care farms can lead to functioning, motivation and well-being. Disability and Rehabilitation, 14645165. https://doi.org/10.3109/09638288.2015.1130177

Ellingsen-Dalskau, L. H., Morken, M., Berget, B., \& Pedersen, I. (2016). Autonomy support and need satisfaction in prevocational programs on care farms: The self-determination theory perspective. Work, 53, 73-85.

https://doi.org/10.3233/wor-152217 
Eriksen, H. R., \& Ihlebæk, C. (2002). Subjective health complaints. Scandinavian Journal of Psychology, 43(2), 101-103. https://doi.org/10.1111/1467$\underline{9450.00274}$

Eriksen, H. R., Ihlebæk, C., \& Ursin, H. (1999). A scoring system for subjective health complaints (SHC). Scandinavian Journal of Public Health, 27(1), 63-72. https://doi.org/10.1177/14034948990270010401

Farholm, A., Halvari, H., Niemiec, C. P., Williams, G. C., \& Deci, E. L. (2016). Changes in return to work among patients in vocational rehabilitation: A selfdetermination theory perspective. Disability and Rehabilitation, 1-8. https://doi.org/10.1080/09638288.2016.1215559

Gagné, M. (2003). The role of autonomy support and autonomy orientation in prosocial behavior engagement. Motivation and Emotion, 27(3), 199-223. https://doi.org/10.1023/A:1025007614869

Gagné, M., \& Deci, E. L. (2005). Self-determination theory and work motivation. Journal of Organizational Behavior, 26, 331-362. https://doi.org/10.1002/job.322

Gjesdal, S., \& Bratberg, E. (2003). Diagnosis and duration of sickness absence as predictors for disability pension: Results from a three-year, multi-register based and prospective study. Scandinavian Journal of Public Health, 31, 246254. https://doi.org/10.1080/14034940210165154

Gjesdal, S., Ringdal, P., Haug, K., \& Maeland, J. (2008). Long-term sickness absence and disability pension with psychiatric diagnoses: A population-based cohort study. Nordic Journal of Psychiatry, 62(4), 294-301. https://doi.org/10.1080/08039480801984024

Hassink, J., \& van Dijk, M. (2006). Farming for health: Green-care farming across Europe and the United States of America. Springer. https://doi.org/10.1007/14020-4541-7

Hine, R., Peacock, J., \& Pretty, J. (2008). Care farming in the UK: Contexts, benefits and links with therapeutic communities. Therapeutic Communities, 29(3), 245260.

Hox, J. J., \& Bechger, T. M. (1998). An introduction to structural equation models. Family Science Review, 11, 354-373. https://doi.org/10.1007/978-3-31916507-3 1

Ihlebæk, C., Brage, S., \& Eriksen, H. (2007). Health complaints and sickness absence in Norway, 1996-2003. Occupational Medicine, 57(1), 43-49. https://doi.org/10.1093/occmed/kql107

Ihlebæk, C., Ellingsen-Dalskau, L. H., \& Berget, B. (2016). Motivations, experiences and challenges of being a care farmer: Results of a survey of Norwegian care farmers. Work, 53(1), 113-122. https://doi.org/10.3233/wor-152220

Ihlebæk, C., Eriksen, H. R., \& Ursin, H. (2002). Prevalence of subjective health complaints (SHC) in Norway. Scandinavian Journal of Public Health, 30(1), 20-29. https://doi.org/10.1080/140349401753481547 
Ihlebæk, C., Eriksen, H. R., \& Ursin, H. (2004). SHC: Et måleinstrument for subjektive helseplager. Tidsskrift for Norsk Psykologforening, 41, 385-387.

Johnston, M. M., \& Finney, S. J. (2010). Measuring basic needs satisfaction:

Evaluating previous research and conducting new psychometric evaluations of the Basic Needs Satisfaction in General Scale. Contemporary Educational Psychology, 35(4), 280-296. https://doi.org/10.1016/j.cedpsych.2010.04.003

Kamaleri, Y., Natvig, B., Ihlebaek, C. M., Benth, J. S., \& Bruusgaard, D. (2008). Number of pain sites is associated with demographic, lifestyle, and healthrelated factors in the general population. European Journal of Pain, 12(6), 742-748. https://doi.org/10.1016/j.ejpain.2007.11.005

Kamaleri, Y., Natvig, B., Ihlebaek, C. M., \& Bruusgaard, D. (2008). Localized or widespread musculoskeletal pain: Does it matter? PAIN, 138(1), 41-46. https://doi.org/10.1016/j.pain.2007.11.002

Kamaleri, Y., Natvig, B., Ihlebaek, C. M., \& Bruusgaard, D. (2009). Does the number of musculoskeletal pain sites predict work disability? A 14-year prospective study. European Journal of Pain, 13(4), 426-430. https://doi.org/10.1016/j.ejpain.2008.05.009

Kjeldsberg, M., Tschudi-Madsen, H., Dalen, I., Straand, J., Bruusgaard, D., \& Natvig, B. (2013). Symptom reporting in a general population in Norway: Results from the Ullensaker study. Scandinavian Journal of Primary Health Care, 31(1), 3642. https://doi.org/10.3109/02813432.2012.751697

Kline, R. B. (2011). Principles and practice of structural equation modeling (3rd ed.). Guilford Press.

Kowal, J., \& Fortier, M. S. (1999). Motivational determinants of flow: Contributions from self-determination theory. The Journal of Social Psychology, 139(3), 355-368. https://doi.org/10.1080/00224549909598391

La Guardia, J. G., Ryan, R. M., Couchman, C. E., \& Deci, E. L. (2000). Within-person variation in security of attachment: A self-determination theory perspective on attachment, need fulfillment, and well-being. Journal of Personality and Social Psychology, 79(3), 367-384. https://doi.org/10.1037/0022-3514.79.3.367

Liberman, R. P. (2008). Recovery from disability: Manual of psychiatric rehabilitation. American Psychiatric Publishing, Inc.

NAV. (2020a). Disability: Statistical notes. https://www.nav.no/no/nav-ogsamfunn/statistikk/aap-nedsatt-arbeidsevne-og-uforetrygdstatistikk/uforetrygd/uforetrygd-statistikknotater kap

NAV. (2020b). Employment preparation training. https://www.nav.no/en/home/benefitsand-services/relatert-informasjon/employment-preparation-training1

OECD. (2010). Sickness, disability and work: Breaking the barriers. A synthesis of findings across OECD countries. https://www.oecd.org/publications/sicknessdisability-and-work-breaking-the-barriers-9789264088856-en.htm

Pavot, W., \& Diener, E. (1993). Review of the Satisfaction with Life Scale.

Psychological Assessment, 5(2), 164-172.

https://psycnet.apa.org/doi/10.1037/1040-3590.5.2.164 
Pavot, W., Diener, E., Colvin, C. R., \& Sandvik, E. (1991). Further validation of the Satisfaction with Life Scale: Evidence for the cross-method convergence of well-being measures. Journal of Personality Assessment, 57(1), 149-161. https://doi.org/10.1207/s15327752jpa5701 17

Pedersen, I., Dalskau, L. H., Ihlebæk, C., \& Patil, G. (2016). Content and key components of vocational rehabilitation on care farms for unemployed people with mental health problems: A case study report. Work, 53(1), 21-30. https://doi.org/10.3233/WOR-152212

Peters, C. L. O., \& Enders, C. (2002). A primer for the estimation of structural equation models in the presence of missing data: Maximum likelihood algorithms. Journal of Targeting, Measurement and Analysis for Marketing, 11(1), 81-95. https://doi.org/10.1057/palgrave.jt.5740069

Piha, K., Laaksonen, M., Martikainen, P., Rahkonen, O., \& Lahelma, E. (2010). Interrelationships between education, occupational class, income and sickness absence. European Journal of Public Health, 20. https://doi.org/10.1093/eurpub/ckp162

Poulsen, O. M., Persson, R., Kristiansen, J., Andersen, L. L., Villadsen, E., \& Ørbæk, P. (2013). Distribution of subjective health complaints, and their association with register-based sickness absence in the Danish working population. Scandinavian Journal of Public Health, 41(2), 150-157. https://doi.org/10.1177/1403494812471909

Ree, E., Odeen, M., Eriksen, H. R., Indahl, A., Ihlebæk, C., Hetland, J., \& Harris, A. (2014). Subjective health complaints and self-rated health: Are expectancies more important than socioeconomic status and workload? International Journal of Behavioral Medicine, 21(3), 411-420. https://doi.org/10.1007/s12529-013-9329-7

Reis, H. T., Sheldon, K. M., Gable, S. L., Roscoe, J., \& Ryan, R. M. (2000). Daily wellbeing: The role of autonomy, competence, and relatedness. Personality and Social Psychology Bulletin, 26(4), 419-435. https://doi.org/10.1177\%2F0146167200266002

Roelen, C. A., Koopmans P.C., \& Groothoff J. W. (2010). Subjective health complaints in relation to sickness absence. Work, 37(1), 15-21. https://doi.org/10.3233/WOR-2010-1052

Rosenfield, S., \& Mouzon, D. (2013). Gender and mental health. In C. S. Aneshensel, J. C. Phelan, \& A. Bierman (Eds.), Handbook of the sociology of mental health (pp. 277-296). Springer Netherlands. https://doi.org/10.1007/978-94-0074276-5 14

Rossler, W. (2006). Psychiatric rehabilitation today: An overview. World Psychiatry, 5(3), 151-157.

Rothman, K.J. (2012). Epidemiology. An introduction (2nd ed.). Oxford University Press.

R. M., \& Deci, E. L. (2000). Self-determination theory and the facilitation of intrinsic motivation, social development, and well-being. American Psychologist, 55(1), 68-78. https://doi.org/10.1037/0003-066X.55.1.68 
Sedgwick, P. (2014). Cross sectional studies: Advantages and disadvantages. BMJ: British Medical Journal, 348. https://doi.org/10.1136/bmj.g2276

Sempik, J., Hine, R., \& Wilcox, D. (2010). Green care: A conceptual framework. A report of the Working Group on the Health Benefits of Green Care, COST Action 866, Green Care in Agriculture. Loughborough University.

Sheldon, K. M., Ryan, R. M., \& Reis, H. T. (1996). What makes for a good day? Competence and autonomy in the day and in the person. Personality and Social Psychology Bulletin, 22, 1270-1279. https://doi.org/10.1177/01461672962212007.

Steigen, A. M., Eriksson, B., Kogstad, R. E., Toft, H. P., \& Bergh, D. (2018). Young adults in nature-based services in Norway: In-group and between-group variations related to mental health problems. Nordic Journal of Social Research, 9. https://doi.org/10.7577/njsr.2301

Sterne, J. A. C., White, I. R., Carlin, J. B., Spratt, M., Royston, P., Kenward, M. G., Wood, A. M., \& Carpenter, J. R. (2009). Multiple imputation for missing data in epidemiological and clinical research: Potential and pitfalls (Vol. 338). https://doi.org/10.1136/bmj.b2393

Tavakol, M., \& Dennick, R. (2011). Making sense of Cronbach's alpha. International Journal of Medical Education, 2, 53-55. https://doi.org/10.5116/ijme.4dfb.8dfd

Thoresen, S. V., Friborg, C., Lundstrøm B., Kausto, J., Kausto, J., Örnelius, K., . . Haram, Ö. (2015). Sickness absence in the Nordic countries. Nordic Social Statistical Committee, Report number: 59:2015. http://norden.divaportal.org/smash/get/diva2:811504/FULLTEXT06.pdf

Turner, E. A., Chandler, M., \& Heffer, R. W. (2009). The influence of parenting styles, achievement motivation, and self-efficacy on academic performance in college students. Journal of College Student Development, 50(3), 337-346. https://doi.org/10.1353/csd.0.0073

Tveito, T. H., Halvorsen, A., Lauvålien, J. V., \& Eriksen, H. R. (2002). Room for everyone in working life? $10 \%$ of the employees $-82 \%$ of the sickness leave. Norsk Epidemiologi, 12(1), 63-68. http://bora.uib.no/handle/1956/1897

Tveito, T. H., Passchier, J., Duivenvoorden, H. J., \& Eriksen, H. R. (2004). Subjective health complaints and health related quality of life in a population of health care workers. Psychology \& Health, 19(2), 247-259. https://doi.org/10.1080/08870440310001613491

Van den Broeck, A., Vansteenkiste, M., De Witte, H., Soenens, B., \& Lens, W. (2010). Capturing autonomy, competence, and relatedness at work: Construction and initial validation of the Work-related Basic Need Satisfaction scale. Journal of Occupational and Organizational Psychology, 83(4), 981-1002. https://doi.org/10.1348/096317909X481382

Vlachopoulos, S. P., \& Michailidou, S. (2006). Development and initial validation of a measure of autonomy, competence, and relatedness in exercise: The Basic Psychological Needs in Exercise Scale. Measurement in Physical Education and Exercise Science, 10(3), 179-201.

https://doi.org/10.1207/s15327841mpee1003 4 
Waddell, G. (2006). Preventing incapacity in people with musculoskeletal disorders. British Medical Bulletin, 77-78, 55-69. https://doi.org/10.1093/bmb/ldl008

Waddell, G., \& Burton, A. K. (2006). Is work good for your health and well-being? TSO. https://doi.org/10.1093/occmed/kql174

WHO. (2016). What is health promotion? http://www.who.int/features/qa/healthpromotion/en/

Øyeflaten, I., Lie, S. A., Ihlebæk, C., \& Eriksen, H. R. (2012). Multiple transitions in sick leave, disability benefits, and return to work: A 4-year follow-up of patients participating in a work-related rehabilitation program. BMC Public Health, 12, 748. https://doi.org/10.1186/1471-2458-12-748

Øyeflaten, I., Opsahl, J., Eriksen, H. R., Braathen, T. N., Lie, S. A., Brage, S., Ihlebæk, C. M., \& Breivik, K. (2016). Subjective health complaints, functional ability, fear avoidance beliefs, and days on sickness benefits after work rehabilitation: A mediation model. BMC Musculoskeletal Disorders, 17(1), 1-12. https://doi.org/10.1186/s12891-016-1084-x 